\title{
Efeito do tratamento de sementes com fungicidas e acibenzolar-S-methyl no controle da ferrugem asiática e crescimento de plântulas em cultivares de soja
}

\author{
Daniel Debona ${ }^{1}$, Gláucia Garcia Figueiró ${ }^{2}$, Gerson Dalla Corte ${ }^{1}$, Lucas Navarini ${ }^{1}$, Lucas da Silva Domingues ${ }^{1} \&$ \\ Ricardo Silveiro Balardin ${ }^{1}$
}

\begin{abstract}
${ }^{1}$ Departamento de Defesa Fitossanitária, Centro de Ciências Rurais, Universidade Federal de Santa Maria - UFSM, Cx. Postal 5025, CEP 97111970, Santa Maria, RS, ${ }^{2}$ Departamento de Engenharia Rural, Fitossanidade e Solos, Universidade Estadual Paulista Júlio de Mesquita Filho UNESP, Ilha Solteira, SP.
\end{abstract}

Autor para correspondência: e-mail: Ricardo Silveiro Balardin balardin@balardin.com.

Data de chegada: 08/11/2007. Aceito para publicação em: 08/12/2008

\section{RESUMO}

Debona, D., Figueiró, G.G., Corte, G.D., Navarini, L., Domingues, L.da S., Balardin, R.S., Efeito do tratamento de sementes com fungicidas e acibenzolar-S-methyl no controle da ferrugem asiática e crescimento de plântulas em cultivares de soja. Summa Phytopathologica, v.35, n.1, p.26-31, 2009

A influência de acibenzolar-S-methyl (ASM), e fungicidas aplicados via tratamento de sementes sobre a ferrugem asiática bem como o crescimento de plântulas de soja foi avaliada em experimento conduzido em casa de vegetação em delineamento inteiramente casualizado com três repetições, utilizando as cultivares de soja 'Agiara', 'M-soy 8000' e 'M-soy 8080'. Os tratamentos foram três doses de ASM (0,05; 0,1 e 0,2 g de i.a. por kg de sementes), ASM (na dose de $0,1 \mathrm{~g}$ de i.a. por $\mathrm{kg}$ de sementes) combinado aos fungicidas flutriafol, pyraclostrobin e azoxystrobin, e a aplicação isolada destes, além de uma testemunha tratada com água. Os resultados mostraram redução da Área Abaixo da Curva de Progresso da Ferrugem (AACPF) com o aumento da dose de ASM nas três cultivares de soja. A utilização isolada do ASM em diferentes doses proporcionou uma redução da AACPF além de apresentar, na maioria dos casos, um efeito sinérgico com os fungicidas, aumentando a eficiência de controle quando comparada às aplicações isoladas. Com exceção do ASM na menor dosagem, todos os tratamentos apresentaram controle superior a 77 \% comparados à testemunha. Em geral, o tratamento de sementes com ASM e fungicidas resultou numa redução da massa seca (MS) em relação à testemunha. A utilização de ASM associado a fungicidas na tentativa de atrasar a infecção da ferrugem asiática da soja nos períodos iniciais da cultura constitui-se em uma alternativa viável para redução do inóculo inicial, entretanto possíveis efeitos fitotóxicos devem ser considerados.

Palavras-chave adicionais: acibenzolar-S-methyl, fungicidas, tratamento de sementes, Phakopsora pachyrhizi, Glycine max.

\section{ABSTRACT}

Debona, D., Figueiró, G.G., Corte, G.D., Navarini, L., Domingues, L.da S., Balardin, R.S., Effect of seed treatment with fungicides and acibenzolar-S-methyl in soybean cultivars on Asian rust control and seedlings growth. Summa Phytopathologica, v.35, n.1, p.26-31, 2009

The influence of acibenzolar-S-methyl (ASM) and fungicides applied as seed treatment on Asian rust control as well as on growth of soybean seedlings were evaluated in a completely randomized experiment with three replications, using the 'Agiara', 'M-soy 8000' and 'M-soy 8080' soybean cultivars. The treatments were three doses of ASM (0,05; 0,1 and 0,2 $\mathrm{g}$ of a.i. for $\mathrm{kg}$ of seeds), ASM (in the dose of $0,1 \mathrm{~g}$ of a.i. for $\mathrm{kg}$ of seeds) combined to the fungicides flutriafol, pyraclostrobin and azoxystrobin, and the isolated application of these as well as a control treated with water. The results showed reduction of Area Under Progress Rust Curve (AUPRC) with the increase of the dose of ASM in the three cultivars of soybean. The isolated use of
ASM in different doses provided reduction of AUPRC as well as it presented synergism with the fungicides, increasing the control efficiency when compared to single applications. Except for ASM applied in the smallest dose, all of the treatments presented control higher than $77 \%$ compared to the control plot. In general, the treatment of seeds with ASM and fungicides resulted in reduction of the dry weight (DW) in relation to control. The use of ASM associated with fungicides attempting to delay the infection of Asian soybean rust in the initial stages constituted a viable alternative for reduction of primary inoculum, however the occurrence of some phytotoxic effects also must be considerated.

Keywords: acibenzolar-S-methyl, fungicides, seed treatment, Phakopsora pachyrhizi, Glycine max.

A ferrugem asiática (Phakopsora pachyrhizi H. Sydow \& Sydow) constitui-se na principal doença da cultura da soja [Glycine max (L.) Merril] no Brasil. Condições climáticas favoráveis ao patógeno na maioria das regiões produtoras, associadas à sua alta virulência e velocidade de dispersão são fatores que tornam a doença extremamente severa afetando significativamente o potencial produtivo da cultura da soja. Plantas severamente atacadas apresentam desfolha antecipada, prejudicando a formação e desenvolvimento de legumes e o peso final de grãos (23).

Embora genes dominantes de resistência tenham sido identificados, a obtenção de resistência tem se mostrado difícil em virtude da alta variabilidade do fungo (17). Este fato obriga produtores 
de diversas regiões brasileiras a realizar repetidas aplicações fungicidas durante o ciclo da cultura na tentativa de controlar a doença, sendo esta a prática mais utilizada no seu controle.

No entanto, novas alternativas devem ser encontradas para auxiliar as práticas de controle tradicionalmente utilizadas. Um dos métodos potenciais de redução da severidade das doenças é a indução dos mecanismos de defesa inerentes das plantas. Este sistema de resistência induzida, conhecido como resistência sistêmica adquirida (SAR), é eficiente contra diversos patógenos, agindo na estimulação de resistência sistêmica após a infecção por um patógeno (16). O amplo espectro da SAR contrasta com a resistência específica proporcionada por genes de resistência utilizados em plantas cultivadas e, portanto, pode estar menos propensa ao fenômeno de quebra de resistência.

Diversos produtos têm apresentado potencial para a resistência sistêmica. Dentre eles, o ácido salicílico (AS), o ácido 2,6 dicloroisonicotínico (INA), sais de potássio e o ácido â-amino butírico (BABA), têm sido relacionados à indução de resistência em plantas contra uma ampla gama de patógenos (18). Porém, o uso destas moléculas tem sido restrito devido à elevada fitotoxidez para a maioria das plantas cultivadas.

Dentre os produtos inorgânicos, o benzo-(1,2,3)-thiadiazole-7carbothioic (acibenzolar-S-methyl ou ASM), é a molécula mais amplamente utilizada, pois tem demonstrado ser um potente ativador da SAR, não apresentando propriedades antimicrobianas, mas incitando aumento na resistência às doenças em muitas espécies de plantas, pela sua ação semelhante ao ácido salicílico na via de transdução do sinal que leva à SAR (1). Para que os próprios mecanismos de defesa da planta ativada demonstrem toda a sua atividade é necessário um período de tempo entre a aplicação do ativador de plantas e o início da infecção. Após a aplicação de ASM, dentro de 4 a 12 horas, ocorre uma indução na produção de proteínas específicas relacionadas com a patogênese, como quitinases, glucanases básicas e perodoxidases ácidas (9).

Resultados demonstrando a ação do ASM na indução da SAR têm sido reportados em vários patossistemas. Benelli et al. (2) verificaram efeito do ASM na indução de resistência em plantas de batata reduzindo os danos causados por Pectobacterium carotovorum subsp. atrosepticum. Segundo Cavalcanti \& Resende (6) a utilização do ASM em cacaueiro pode representar uma alternativa eficiente na busca de medidas de manejo integrado de doenças importantes da cultura como a vassoura-de-bruxa (Crinipellis Perniciosa) e a murcha de Verticillium (Verticillium dahliae). Aplicações exógenas de ASM em folhas de fumo têm sido associadas à ativação de vários genes ligados a SAR, levando a uma intensa proteção da planta contra vários patógenos (7).

Benhamou \& Bélanger (3) demonstraram que a aplicação do indutor ASM em folhas de pepino antes da inoculação com Pythium ultimum desencadeou uma série de reações de defesa na planta que resultaram na criação de um ambiente fungitóxico, que protegeu as raízes pela restrição do crescimento do patógeno aos demais tecidos. Em soja, a inclusão do ASM nos programas de controle químico aumentou a eficácia dos fungicidas no controle de doenças de final de ciclo $\left(\mathrm{DFC}_{\mathrm{s}}\right)$ na maioria dos casos, tendo impactos positivos na redução da severidade, aumento da área foliar verde e no rendimento de grãos (8). Isso provavelmente se deve ao fato de que o indutor de resistência possui efeito sinérgico com os fungicidas no controle das doençasalvo (15).

A ocorrência cada vez mais precoce de $P$. pachyrhizi em algumas regiões do país, observada já no início da fase vegetativa tem obrigado a realização de pulverizações foliares de fungicidas cada vez mais antecipadas aumentando o número de aplicações durante o ciclo da cultura da soja. O tratamento de sementes com produtos que apresentem longo período residual pode se constituir numa alternativa viável no manejo da doença, podendo inclusive reduzir esse número de aplicações. O efeito do tratamento de sementes com diferentes doses de ASM bem como de fungicidas isolados ou misturados a ele sobre a intensidade da ferrugem asiática e o crescimento das plântulas de três cultivares de soja foi avaliado neste experimento.

\section{MATERIAL E MÉTODOS}

O experimento foi desenvolvido em casa de vegetação do Departamento de Defesa Fitossanitária da Universidade Federal de Santa Maria - Santa Maria - RS (UFSM), nos anos de 2006 e 2007. A casa de vegetação apresenta um sistema de refrigeração, nebulização e aquecimento, possibilitando o controle parcial da temperatura e da umidade relativa do ar.

Um quilograma de sementes das cultivares de soja 'M-soy 8000', 'M-soy 8080' e 'Agiara' foi tratado com acibenzolar-S-methyl (0,05; 0,1 e 0,2 g de i.a.) e os fungicidas flutriafol (3 g de i.a.), pyraclostrobin (0,75 g de i.a.), azoxystrobin (0,75 g de i.a.) isolados e em mistura com o indutor. O ASM foi misturado aos fungicidas na dose de $0,1 \mathrm{~g}$ de i.a. As sementes foram tratadas com a calda fungicida ou do indutor no volume de $6 \mathrm{~mL}$ para cada $\mathrm{kg}$ de sementes, em sacos plásticos, e agitadas até uma deposição uniforme na superfície das sementes. Em adição, utilizou-se um tratamento testemunha em cujas sementes foi aplicado água, sendo esta o veículo utilizado para completar o volume da calda dos tratamentos supracitados.

Cinqüenta sementes de cada cultivar, dispostas em cinco linhas, foram semeadas em bandejas plásticas de $23 \mathrm{~cm}$ x $17 \mathrm{~cm}$ x 5,5 cm contendo substrato estéril à base de turfa $\left(\right.$ Plantmax $\left.^{\circledR}\right)$. Adicionalmente, foi efetuada a semeadura em copos plásticos de $500 \mathrm{~mL}$ com cinco sementes cada, preenchidos com o mesmo substrato, sendo desbastado para três plântulas de soja por copo logo após a emergência. Cada tratamento correspondeu a três bandejas e três copos. As plântulas crescidas nos copos não foram inoculadas.

As inoculações com uredosporos de $P$. pachyrhizi foram realizadas aos 7, 14 e 21 dias após a emergência (DAE), sendo efetuadas no período noturno a fim de manter o molhamento foliar necessário para a infecção do patógeno. O inóculo foi obtido a partir da coleta a seco de uredosporos em plantas de soja exibindo intensa esporulação do patógeno com o auxílio de um succionador a vácuo movido à bateria de 12 volts. A suspensão de esporos foi composta por água, espalhanteadesivo (Tween 80 ) a $0,5 \%$ do volume da calda e uredosporos de $P$. pachyrhizi, sendo calibrada para uma concentração de $2 \times 10^{5}$ esporos. $\mathrm{mL}^{-1}$. A deposição dos uredosporos do fungo foi realizada em ambas as faces das folhas até o completo molhamento foliar evitandose o escorrimento, sendo pulverizados com um aerógrafo propelido a $\mathrm{CO}_{2}$, ajustado para uma pressão de trabalho de 0,5 bar.

Ao longo do estudo, as plântulas foram mantidas sob condições de umidade relativa superior a $80 \%$ através de nebulizações periódicas de 15 min.dia ${ }^{-1}$ e temperatura do ar entre $15^{\circ} \mathrm{C}$ e $30^{\circ} \mathrm{C}$.

A severidade da ferrugem da soja foi obtida através de notas visuais da porcentagem da área foliar com sintomas da doença conforme escala proposta por Godoy et al. (11). As avaliações foram realizadas aos 14, 21 e 28 dias após a emergência (DAE). Os dados de severidade foram utilizados para o cálculo da Área Abaixo da Curva de Progresso da Ferrugem (AACPF). Também foi avaliado o comprimento de raiz, comprimento de parte aérea e a massa seca de ambos aos 21 DAE.

As plântulas crescidas nos copos foram utilizadas para análise de 
comprimento e massa seca. As raízes foram lavadas em água corrente para a aferição do comprimento de raiz e de parte aérea. A determinação do comprimento de parte aérea e radicular foi obtida a partir da medição com paquímetro digital desde a região do colo da plântula até o meristema apical e daquele ao ápice da raiz principal, respectivamente. Posteriormente, as plântulas foram seccionadas na região do colo, sendo as raízes e a parte aérea acondicionadas separadamente em sacos de papel e colocadas em estufa com circulação forçada de ar sob temperatura de $60^{\circ} \mathrm{C} \pm 5^{\circ} \mathrm{C}$, até atingir peso constante. Por fim, foi determinada a massa seca da parte aérea e radicular em balança de precisão $(0,001 \mathrm{~g})$.

O experimento foi conduzido em delineamento inteiramente casualizado com três repetições, onde cada parcela foi representada por três bandejas para avaliação de severidade e três copos plásticos para a determinação do comprimento de parte aérea e radicular além da massa seca de ambos. Os dados obtidos foram submetidos à análise da variância complementada pelo teste de Tukey $(\mathrm{p}<0,05)$ para comparação múltipla de médias. As análises foram realizadas com o auxílio do software PlotIT versão 3.2 para ambiente de Windows.

\section{RESULTADOS E DISCUSSÃO}

O tratamento de sementes com diferentes doses de ASM reduziu a intensidade da ferrugem da soja nos estádios iniciais da cultura. Os fungicidas isolados ou em mistura com ASM proporcionaram uma significativa supressão da infecção de $P$. pachyrhizi nas três cultivares. As maiores doses de ASM afetaram o crescimento e o desenvolvimento das plântulas, sendo que sua associação a fungicidas se mostrou diferencial para cada cultivar.

A Área Abaixo da Curva de Progresso da Ferrugem (AACPF) no tratamento testemunha foi de 250,25, 289,45 e 301,00 para as cultivares 'M-soy 8000', 'M-soy 8080’e 'Agiara', respectivamente (Tabela 01). Considerando o emprego isolado do ASM, foi observada redução na AACPF proporcional ao aumento na dose do indutor nas três cultivares (Figura 01), sendo a cultivar 'M-soy 8080' a mais responsiva ao aumento da dose de 0,05 para $0,1 \mathrm{~g}$ de i.a., conferindo uma redução de
239,98 para 68,54, respectivamente. Estes resultados estão de acordo com os obtidos por Maxson-Stein et al. (14) onde os autores verificaram redução na extensão do cancro causado por Erwinia amylovora em macieira quando a dose de ASM foi aumentada de $0 \mathrm{mg}$ a 300 mg.de i.a. $L^{-1}$ em aplicações do produto via foliar. Da mesma forma, Guzzo et al. (12) ao testar o efeito de diferentes concentrações de ASM aplicadas em folhas de cafeeiro sobre o número de lesões de Hemileia vastatrix mostraram que o aumento na concentração do indutor de 10 ppm para 50 ppm proporcionou redução de 66,5\% para níveis superiores a $86 \%$ a partir desta dose, atingindo $97 \%$ na concentração de 400 ppm. Trabalhos conduzidos por Godard et al. (10) também mostraram que a indução de resistência de couve-flor contra míldio (Peronospora parasitica) é dependente da dose. Em um destes estudos, os autores, ao avaliar 22 plantas, observaram que 12 e 19 delas mostraram-se resistentes quando ocorreu um aumento na dose de ASM de 0,03 para 0,075 mg de i.a..mL $\mathrm{mL}^{-1}$ de água, respectivamente.

Em contrapartida, Resende et al. (20) ao testar o efeito de duas (20 e 60 g por 100 L de água) e três (20, 80 e 150 g por 100 L de água)

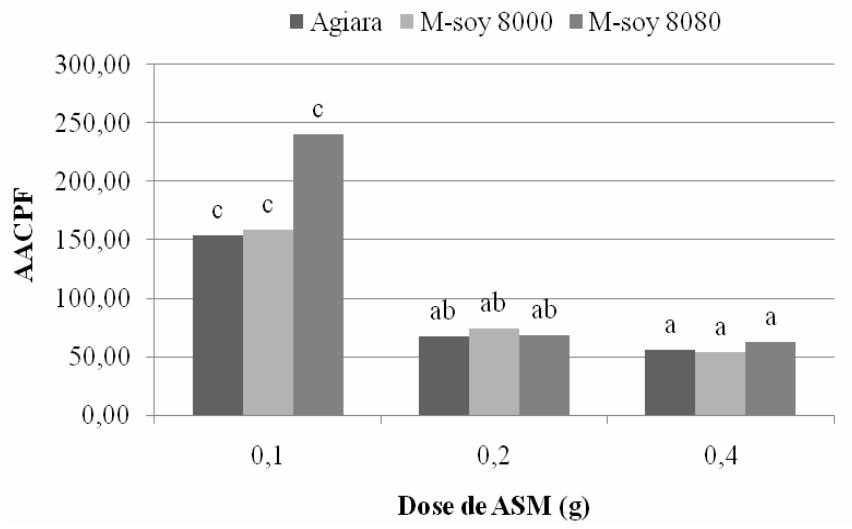

Figura 1. Efeito da dose de acibenzolar-S-methyl (ASM) sobre a Área Abaixo da Curva de Progresso da Ferrugem (AACPF) em três cultivares de soja. Barras seguidas de mesma letra dentro de cada cultivar apresentam valores sem diferença significativa entre si pelo teste de Tukey $(p<0,05)$.

Tabela 1. - Área Abaixo da Curva de Progresso de Ferrugem (AACPF) e controle da doença referente a diferentes produtos utilizados no tratamento de sementes em três cultivares de soja.

\begin{tabular}{|c|c|c|c|c|c|c|c|}
\hline & \multirow[b]{2}{*}{ Tratamentos } & \multicolumn{2}{|c|}{ Agiara } & \multicolumn{2}{|c|}{ M-soy 8000} & \multicolumn{2}{|c|}{ M-soy 8080} \\
\hline & & $\mathrm{AACPF}^{4}$ & Controle (\%) & $\mathrm{AACPF}^{4}$ & Controle (\%) & $\mathrm{AACPF}^{4}$ & Controle (\%) \\
\hline 1 & Testemunha & 301,00 e & 0 & $250,25 \mathrm{~g}$ & 0 & $289,45 \mathrm{~g}$ & 0 \\
\hline 3 & $\mathrm{ASM}^{1}$ & 67,67 с & 77,5 & 74,43 e & 70,3 & $68,54 \mathrm{~cd}$ & 76,32 \\
\hline 4 & $\mathrm{ASM}^{1}$ & 56,00 с & 81,4 & 53,9 c & 78,5 & $62,30 \mathrm{c}$ & 78,48 \\
\hline 5 & $\mathrm{ASM}^{2}+$ flutriafol $^{3}$ & 16,22 а & 94,6 & 14,12 a & 94,4 & 16,68 а & 94,24 \\
\hline 7 & $\mathrm{ASM}^{2}+$ azoxystrobin $^{3}$ & $30,45 \mathrm{~b}$ & 89,9 & $56 \mathrm{~cd}$ & 77,6 & $35,93 \mathrm{~b}$ & 87,59 \\
\hline 8 & Flutriafol $^{3}$ & $28,82 \mathrm{ab}$ & 90,4 & $33,95 \mathrm{~b}$ & 86,4 & 17,50 a & 93,95 \\
\hline 9 & Pyraclostrobin $^{3}$ & 62,77 с & 79,1 & 66,85 de & 73,3 & 84,00 de & 70,98 \\
\hline 10 & Azoxystrobin $^{3}$ & $26,95 \mathrm{ab}$ & 91 & $29,75 \mathrm{~b}$ & 88,1 & 44,22 b & 84,72 \\
\hline $\mathrm{CV}$ & & \multicolumn{2}{|c|}{6,12} & \multicolumn{2}{|c|}{5,24} & \multicolumn{2}{|c|}{6,23} \\
\hline
\end{tabular}

${ }^{1}$ Nos tratamentos 2, 3 e 4 a dose de ASM empregada foi de 0,1 g 0,2 g e 0,4 g de produto comercial (50 \% de i.a.) para o tratamento de 1 kg de sementes, respectivamente.

${ }^{2} \mathrm{~A}$ dose de ASM , quando misturado ao fungicida, foi de $0,2 \mathrm{~g}$ do produto comercial (50 \% de i.a.) para $1 \mathrm{~kg}$ de sementes.

${ }^{3}$ A dose empregada para o tratamento de $1 \mathrm{~kg}$ de sementes, concentração de ingrediente ativo no produto comercial e formulação de flutriafol, pyraclostrobin e azoxystrobin utilizadas foram respectivamente: 3 g (2,5 DS), 1,5 mL (250 CE) e 0,75 g (500 WG).

${ }^{4}$ Médias seguidas de mesma letra nas colunas não diferem entre si pelo teste de Tukey $(\mathrm{p}<0,05)$. 
doses de ASM sobre plântulas de cacaueiro contra Verticillium dahliae e Crinipellis perniciosa, respectivamente, observaram inconsistência nos dados quando analisaram a porcentagem de controle dos patógenos. No primeiro caso, as doses de 20 e 60 g por $100 \mathrm{~L}$ de água não diferiram entre si no controle da murcha de Verticillium. No segundo, maior controle foi obtido na dose de 150 g, não diferindo, porém, da menor dose. Além disso, nesse mesmo experimento, os autores também observaram que a indução de defesa devida à aplicação do ASM é dependente do genótipo do hospedeiro, corroborando a variação de resposta observada na AACPF entre as cultivares analisadas neste experimento quanto ao uso do indutor.

Foi observado efeito sinérgico entre ASM e pyraclostrobin. na cultivar 'Agiara' (Tabela 01). Neste caso, foi verificada redução de 47 \% na AACPF em comparação ao uso isolado do fungicida, não ocorrendo diferença significativa para os demais fungicidas.

Para a cultivar 'M-soy 8000', a menor AACPF $(14,12)$ foi observada no tratamento ASM + flutriafol, havendo diferença significativa em relação aos demais tratamentos. O fungicida azoxystrobin associado ao ASM apresentou um aumento de 29,75 para 56,00 no valor de AACPF em relação ao fungicida aplicado sozinho. Já o fungicida pyraclostrobin não foi afetado pela mistura com indutor.

Com relação à cultivar 'M-soy 8080’ mais uma vez os melhores tratamentos foram aqueles nos quais o flutriafol foi aplicado isoladamente ou misturado ao ASM, sendo comparáveis estatisticamente entre si, mas ocorrendo diferença significativa em relação aos demais tratamentos. A utilização de flutriafol + ASM proporcionou uma redução de 94,2 \% na AACPF em comparação à testemunha.

A associação entre ASM e estreptomicina em macieira também foi mais efetiva em limitar o desenvolvimento do cancro por Erwinia amylovora do que o indutor (utilizado na dose $75 \mathrm{mg}$ de ingrediente ativo por litro) e o bactericida (aplicado na dose de $100 \mathrm{mg}$ de ingrediente ativo por litro) isolados (14). Do mesmo modo, a aplicação conjunta de ASM e oxicloreto de cobre foi mais efetiva no controle de Pseudomonas syringae em fumo do que a aplicação de oxicloreto sozinho, embora este não tenha incrementado a ação do indutor (7). Molina et al. (15) também observaram que ASM e metalaxyl foram efetivos no controle da infecção pelo fungo quando ambos eram aplicados juntos. Contrariamente, estudos realizados com tomate avaliando o efeito de diferentes programas de controle sobre a pinta preta (Alternaria solani) não encontraram aumento no controle da doença quando o ASM foi misturado aos fungicidas mancozeb, azoxystrobin e difenoconazole (22).

Em geral, as doses de ASM não influenciaram o comprimento da parte aérea das plântulas de soja avaliado aos 21 DAE (Tabela 02). Apesar disso, observou-se uma tendência de o indutor aumentar o comprimento de parte aérea para todas as doses testadas em comparação à testemunha embora apenas na cultivar 'M-soy 8080' tal diferença tenha sido significativa. Tais resultados discordam daqueles obtidos por Buzi et al. (5) onde os autores observaram que embora o ASM aplicado em tratamento de sementes tenha conferido proteção a plantas de melão contra Sclerotinia sclerotiorum e Didymella bryoniae, o mesmo causou redução na taxa de crescimento das plântulas. O aumento na dose de ASM de 0,015 para $0,75 \mathrm{mg}$ de i.a. $\mathrm{mL}^{-1}$ de água aplicadas sobre plantas de couve-flor também reduziu a estatura das plantas de 5,9 \% para $38,3 \%$, respectivamente $(10)$.

De qualquer modo, o aumento no comprimento da parte aérea não esteve correlacionado com incremento na sua massa seca (Tabela 02). Na cultivar 'Agiara', o tratamento contendo somente ASM na dose de 0,05 g de i.a. por quilograma de sementes conferiu uma redução de cerca de 20 \% na matéria seca das plântulas em relação à testemunha. Embora o indutor tenha proporcionado maior crescimento das plântulas tal efeito provavelmente tenha sido acompanhado de um consumo de energia pelo metabolismo secundário dos processos induzidos de defesa proporcionando uma diminuição de massa seca.

De acordo com Soares \& Maringoni (21) o tratamento de sementes de feijoeiro com ASM na dose de 25 g de i.a. por $100 \mathrm{~kg}$ de sementes teve efeito fitotóxico reduzindo a germinação de sementes e promovendo crescimento anormal de plantas. Segundo Pascholati (19) algumas observações têm sido feitas sugerindo que efeitos colaterais de ativadores de resistência possam, sob certas circunstâncias, afetar negativamente a fisiologia da planta ou que a indução de resistência tenha um custo energético para ela, corroborando com os dados de

Tabela 2. Efeito de ASM e fungicidas utilizados de forma isolada e em associação no tratamento de sementes de três cultivares de soja sobre o comprimento da parte aérea (CPA) e massa seca de parte aérea (MSPA) das plântulas aos 21 DAE.

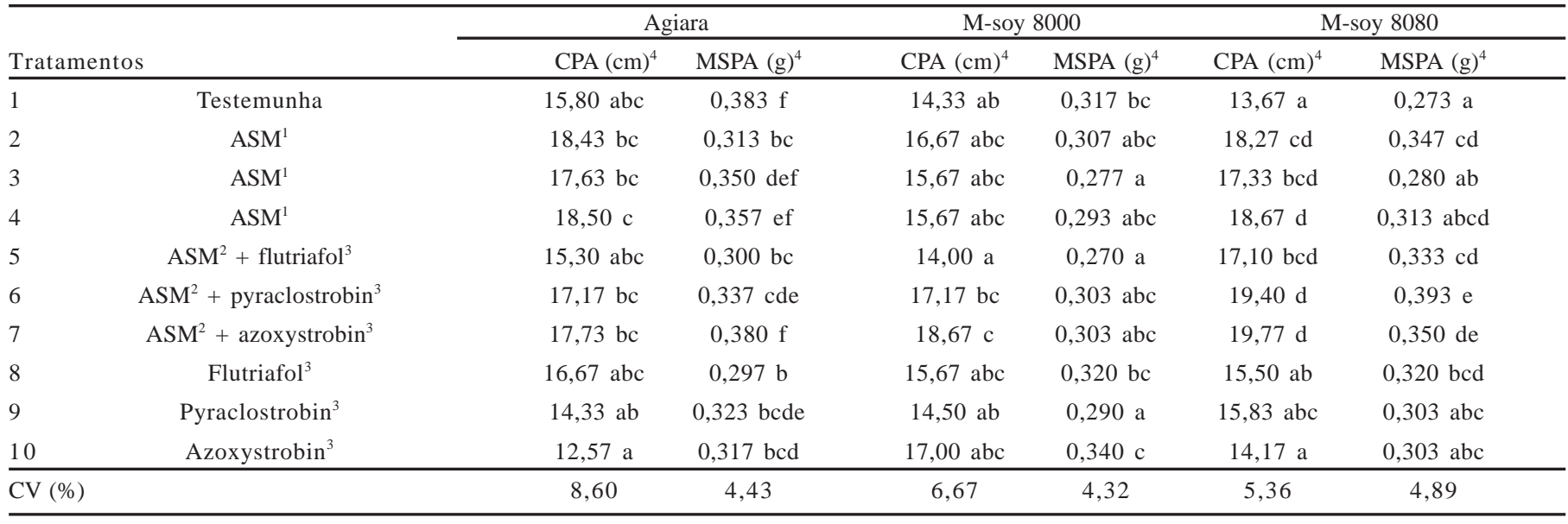

${ }^{1}$ Nos tratamentos 2, 3 e 4 a dose de ASM empregada foi de $0,1 \mathrm{~g} 0,2 \mathrm{~g}$ e $0,4 \mathrm{~g}$ de produto comercial ( $50 \%$ de i.a.) para o tratamento de $1 \mathrm{~kg}$ de sementes, respectivamente.

${ }^{2} \mathrm{~A}$ dose de ASM , quando misturado ao fungicida, foi de $0,2 \mathrm{~g}$ do produto comercial (50 \% de i.a.) para $1 \mathrm{~kg}$ de sementes.

${ }^{3}$ A dose empregada para o tratamento de $1 \mathrm{~kg}$ de sementes, concentração de ingrediente ativo no produto comercial e formulação de flutriafol, pyraclostrobin e azoxystrobin utilizadas foram respectivamente: $3 \mathrm{~g}$ (2,5 DS), 1,5 $\mathrm{mL}$ (250 CE) e 0,75 g (500 WG).

${ }^{4}$ Médias seguidas de mesma letra nas colunas não diferem entre si pelo teste de Tukey $(\mathrm{p}<0,05)$. 
Tabela3. Variação no comprimento radicular (CR) e massa seca de raiz (MSR) de plântulas aos 21 DAE em diferentes cultivares de soja submetidas ao tratamento de sementes com diferentes produtos.

\begin{tabular}{|c|c|c|c|c|c|c|c|}
\hline & \multirow[b]{2}{*}{ Tratamentos } & \multicolumn{2}{|c|}{$\begin{array}{l}\text { Agiara } \\
\text { A }\end{array}$} & \multicolumn{2}{|c|}{ Nidera 8000} & \multicolumn{2}{|c|}{ Msoy 8080} \\
\hline & & $\mathrm{CR}(\mathrm{cm})^{4}$ & $\operatorname{MSR}(g)^{4}$ & $\mathrm{CR}(\mathrm{cm})^{4}$ & $\operatorname{MSR}(g)^{4}$ & $\mathrm{CR}(\mathrm{cm})^{4}$ & $\operatorname{MSR}(g)^{4}$ \\
\hline$\overline{1}$ & Testemunha & $20,33 \mathrm{~d}$ & $0,157 \mathrm{~d}$ & $16,83 \mathrm{ab}$ & 0,150 e & $26,00 \mathrm{~d}$ & 0,133 def \\
\hline 3 & ASM & $15,17 \mathrm{ab}$ & 0,130 abc & 20,00 bc & 0,120 с & $19,33 \mathrm{ab}$ & $0,113 \mathrm{ab}$ \\
\hline 4 & ASM & 16,37 abc & $0,117 \mathrm{ab}$ & 15,83 a & $0,100 \mathrm{~b}$ & 16,83 a & $0,110 \mathrm{a}$ \\
\hline 5 & ASM + Flutriafol & $19,33 \mathrm{~cd}$ & 0,123 abc & 15,67 a & $0,100 \mathrm{~b}$ & 16,83 a & 0,123 abcd \\
\hline 7 & ASM $^{2}+$ Azoxistrobin $^{3}$ & 17,23 bcd & $0,113 \mathrm{ab}$ & $16,67 \mathrm{ab}$ & $0,083 \mathrm{ab}$ & $19,17 \mathrm{ab}$ & $0,117 \mathrm{abc}$ \\
\hline 8 & Flutriafol $^{3}$ & $14,60 \mathrm{ab}$ & 0,110 a & 20,50 c & $0,127 \mathrm{~cd}$ & $23,60 \mathrm{~cd}$ & 0,127 bcde \\
\hline 9 & Pyraclostrobin $^{3}$ & 17,17 bcd & 0,133 bc & 16,33 а & 0,143 de & 22,33 bcd & 0,140 ef \\
\hline 10 & Azoxistrobin $^{3}$ & $14,83 \mathrm{ab}$ & $0,143 \mathrm{~cd}$ & 18,83 abc & 0,143 de & $24,33 \mathrm{~cd}$ & 0,140 ef \\
\hline C.V. (\%) & & 6,68 & 5,59 & 6,94 & 5,65 & 4,34 & 6,73 \\
\hline
\end{tabular}

${ }^{1}$ Nos tratamentos 2, 3 e 4 a dose de ASM empregada foi de $0,1 \mathrm{~g} \mathrm{0,2} \mathrm{g}$ e $0,4 \mathrm{~g}$ de produto comercial (50 \% de i.a.) para o tratamento de $1 \mathrm{~kg}$ de sementes, respectivamente.

${ }^{2} \mathrm{~A}$ dose de ASM , quando misturado ao fungicida, foi de $0,2 \mathrm{~g}$ do produto comercial (50 \% de i.a.) para $1 \mathrm{~kg}$ de sementes.

${ }^{3}$ A dose empregada para o tratamento de $1 \mathrm{~kg}$ de sementes, concentração de ingrediente ativo no produto comercial e formulação de flutriafol, pyraclostrobin e azoxystrobin utilizadas foram respectivamente: $3 \mathrm{~g}$ (2,5 DS), 1,5 $\mathrm{mL}$ (250 CE) e 0,75 g (500 WG).

${ }^{4}$ Médias seguidas de mesma letra nas colunas não diferem entre si pelo teste de Tukey $(\mathrm{p}<0,05)$.

diminuição de massa seca obtidos neste experimento.

Os resultados do comprimento radicular bem como de sua massa seca são apresentados na Tabela 03. Nela, verifica-se que a aplicação de ASM, independente da dose empregada, reduziu significativamente o comprimento radicular de plântulas das cultivares 'Agiara' e 'M-soy 8080' em comparação à testemunha. Com relação à dose do indutor, o aumento da mesma de 0,05 para 0,2 g de i.a. por quilograma de sementes também resultou em redução no comprimento de raiz na maioria dos casos. Tendência similar foi observada para a massa seca de raiz (Tabela 03). Nas cultivares 'Agiara' e 'M-soy 8000', a testemunha apresentou os maiores valores de massa seca (0,157 e 0,150 g, respectivamente), embora não tenha diferido de pyraclostrobin e ASM + flutriafol para a primeira cultivar e de pyraclostrobin e azoxystrobin para a segunda cultivar. Na cultivar 'M-soy 8080', o tratamento ASM + pyraclostrobin resultou na maior massa seca de raiz $(0,147)$, sendo estatisticamente comparável aos tratamentos pyraclostrobin, azoxystrobin e à própria testemunha.

A ativação dos mecanismos de defesa promovidas pelo ASM envolve o aumento na atividade de determinadas proteínas (proteínas PR), como â-1,3-glucanases (4) e quitinases (1), além de peroxidases e polifenol oxidases, podendo variar de acordo com o genótipo do hospedeiro (20). Segundo Heil et al. (13) a produção dessas enzimas requeridas para a ativação da SAR pode competir com proteínas necessárias aos processos básicos da planta, podendo comprometer o crescimento dela. Estes mesmos autores mostraram que plantas de trigo tratadas com ASM apresentaram redução na biomassa de parte aérea e radicular em relação à testemunha.

O tratamento de sementes com ASM associado a fungicidas na tentativa de atrasar a infecção da ferrugem asiática da soja nos períodos iniciais da cultura constitui-se em uma alternativa viável para redução do inóculo inicial, entretanto deve-se atentar para possíveis efeitos fitotóxicos. Os resultados aqui apresentados mostraram diferenças entre cultivares de soja o que remete à realização de estudos varietais em campo a fim de quantificar a estabilidade do uso dessa alternativa no controle de ferrugem.

\section{REFERÊNCIAS BIBLIOGRÁFICAS}

1.Baysal, O.; Soylu E. M.; Soylu, S. Induction of defence-related enzymes and resistance by the plant activator acibenzolar-S-methyl in tomato seedlings against bacterial canker caused by Clavibacter michiganensis ssp. michiganensis. Plant Pathology, Bangor, v.52, p.747-753, 2003.

2.Benelli, A.I.H.; Denardin, N.D.; Forcelini, C.A. Ação do acibenzolar-S-metil aplicado em tubérculos e plantas de batata contra canela preta, incitada por Pectobacterium carotovorum subsp. atrosepticum atípica. Fitopatologia Brasileira, Brasília, v.29, p.263267, 2004.

3.Benhamou, N.; Bélanger, R.R. Induction of systemic resistance to Pythium damping-off in cucumber plants by benzothiadiazole: ultrastructure and cytochemistry of the host response. Plant Journal, Gainesville, v.14, p.13-21, 1998.

4. Boksi, A.I.; Morris, S.C.; Deverall, B.J. Effects of benzothiadiazole and acetylsalicylic acid on â-1,3-glucanase activity and disease resistance in potato. Plant Pathology, Bangor, v.52, p.2227, 2003.

5.Buzi, A.; Chilosi, G.; De Sillo, D.; Magro, P. Induction of Resistance in Melon to Didymella bryoniae and Sclerotinia sclerotiorum by Seed Treatments with Acibenzolar-S-methyl and Methyl Jasmonate but not with Salicylic Acid. Journal of Phytopathology, Berlin, v.152, p.34-42, 2004.

6.Cavalcanti, L.S.; Resende, M.L.V.. Effect of time and dosage of acibenzolar-S-methyl applications in inducing resistance to Verticillium wilt in cocoa seedlings. Fitopatologia Brasileira, Brasília, v.30, p.67-71, 2005 .

7.Cole, D.L. The efficacy of acibenzolar-S-methyl, an inducer of systemic acquired resistance, against bacterial and fungal diseases of tobacco. Crop Protection, Rotterdam, v.18, p.267-273, 1999.

8.Dallagnol, L.J.; Navarini, L.; Ugalde, M.G.; Balardin, R.S.; Catellam, R. Utilização de Acibenzolar-S-Methyl para Controle de Doenças Foliares da Soja. Summa Phytopathologica, Botucatu, v.32, n.3, p.255-259, 2006.

9.Friedrich, L.; Lawton, K.; Ruess, W.; Masner, P.; Specker, N.; Gut, R.M.; Meier, B.; Dincher, S.; Staub, T.; Uknes, S.; MétrauX, J.P.; Kessmann, H.; Ryals, J. A benzothiadiazole derivative induces systemic acquired resistance in tobacco. Plant Journal, Gainesville, v.10, p.61-70, 1996.

10. Godard, J.F.; Ziadi, S.; Monot, C.; Le Corre, D.; Silue, D. Benzothiadiazole (BTH) induces resistance in cauliflower (Brassica ole- 
racea var botrytis) to downy mildew of crucifers caused by Peronospora parasitica. Crop Protection, Rotterdam, v.18, p.397405, 1999.

11.Godoy, C.V., Koga, L.J.; Canteri, M.G. Diagrammatic scale for assessment of soybean rust severity. Fitopatologia Brasileira, Brasília, v.31, p.63-68, 2006.

12.Guzzo, S.D.; Castro, R.M.de; Kida, K.; Martins, E.M.F Ação protetora do acibenzolar-s-methyl em plantas de cafeeiro contra ferrugem. Arquivos do Instituto Biológico, São Paulo, v.68, p.89-94, 2001.

13.Heil, M.; Hilpert, A.; Werner, K.; Linsenmair, K.E. Reduced growth and seed set following chemical induction of pathogen defence: does systemic acquired resistance (SAR) incur allocation costs? Journal of Ecology, Londres, v.88, p.645-654, 2000.

14.Maxson-Stein, K.; He, S.; Hammerschmidt, R.; Jones, A. L. Effect of treating apple trees with acibenzolar-S-methyl on fire blight and expression of pathogenesis-related protein genes. Plant Disease, St. Paul, v.86, p.785-790, 2002.

15.Molina, A.; Hunt, D.M.; Ryals, J.A. Impaired fungicide activity in plants blocked in diseases resistance signal transduction. The Plant Cell, Bethesda, v. 10, n. 11, p. 1903-1914, 1998.

16. Moraes, M.G. Mecanismos da resistência sistêmica adquirida em plantas. Revisão Anual de Patologia de Plantas, Passo Fundo, p.261-84, 1998

17.Oliveira, A.C.B.; Godoy, C.V.; Martins, M.C. Avaliação da tole- rância de cultivares de soja à ferrugem asiática no Oeste da Bahia. Fitopatologia Brasileira, Brasília, v.30, p.658-662, 2005.

18.Oostendorp, M.; Kunz, W.; Dietrich, B.; Staub, T. Induced disease resistance in plants by chemicals. European Journal of Plant Pathology, Wageningen, v.107, p.19-28, 2001.

19.Pascholati, S.F., Bioquímica fitopatológica e indução de resistência. Fitopatologia brasileira, Brasília, v.24, supl., p.241, 1999. 20.Resende, M.L.V.; Nojosa, G.B.A.; Cavalcanti, L.S.; Aguilar, M.A.G.; Silva, J.O.; Perez, L.H.C.P.; Andrade, G.C.G.; Carvalho, G.A.; Castro, R.M. Induction of resistance in cocoa against Crinipellis perniciosa and Verticillium dahliae by acibenzolar- S-methyl (ASM). Plant Pathology, Bangor, v.51, p.621628, 2002.

21.Soares, R.M., Maringoni, A.C., Efeito de acibenzolar-S-methyl sobre a germinação e desempenho de sementes de feijoeiro e na indução de resistência à murcha-de-Curtobacterium. Summa Phytopathologica, Botucatu, v.28, p.41-45, 2002.

22.Töfoli, J.G.; Domingues, R.J. Controle da pinta preta do tomateiro com o uso de acibenzolar-s-metil isolado, em mistura com fungicidas e em programas de aplicação. Arquivos do Instituto Biológico, São Paulo, v.72, p.481-487, 2005.

23.Yang, X.B.; Tschanz, A.T.; Dowler, W.M.; Wang, T.C. Development of yield loss models in relation to reductions of components of soybeans infected with Phakopsora pachyrhizi. Phytopathology, St. Paul, v.81, p.1420-1426, 1991. 